\title{
Influência da textura do solo na seletividade do herbicida fomesafen aplicado em pré-emergência do algodoeiro ${ }^{1}$
}

\section{Influence of soil texture on selectivity of fomesafen applied in cotton pre-emergence}

\author{
Ricardo André Kloster Karpinski ${ }^{2}$, Antonio Mendes de Oliveira Neto ${ }^{3}$, Naiara Guerra ${ }^{4}$, Jamil \\ Constantin ${ }^{5}$, Rubem Silvério de Oliveira $\mathrm{Jr}^{5}$, Cleber Daniel de Goes Maciel ${ }^{6}$, André Augusto \\ Pazinato da Silva ${ }^{2}$
}

Resumo - A seletividade de herbicidas aplicados em pré-emergência depende das características do solo cultivado. Neste contexto, o objetivo deste trabalho foi avaliar a seletividade do herbicida fomesafen à cultura do algodoeiro em solos de classe textural contrastantes. $\mathrm{O}$ experimento foi realizado em casa de vegetação no delineamento experimental inteiramente casualizado, com cinco repetições. Os tratamentos foram arranjados em esquema fatorial 5 x 2, com o primeiro nível correspondente a cinco doses de fomesafen $\left(0,175,350,525 \mathrm{e}^{2} 700 \mathrm{~g} \mathrm{ha}^{-1}\right)$ e o segundo fator de dois solos de textura contrastante: textura franco arenosa $\left(200 \mathrm{~g} \mathrm{~kg}^{-1}\right.$ de argila, $40 \mathrm{~g} \mathrm{~kg}^{-1} \mathrm{de} \mathrm{silte} \mathrm{e}$ $760 \mathrm{~g} \mathrm{~kg}^{-1}$ de areia, $\mathrm{pH}$ de 4,47 e 1,59\% de M.O.) e muito argilosa (760 g kg-1 de argila, $110 \mathrm{~g} \mathrm{~kg}^{-1}$ de silte e $130 \mathrm{~g} \mathrm{~kg}^{-1}$ de areia, $\mathrm{pH}$ 5,7 e 2,30\% de M.O.). As avaliações realizadas foram: a contagem de plantas emergidas aos 7 e 14 dias após a emergência (DAE), a fitointoxicação realizada aos sete, 14 e 21 DAE. Aos 35 DAE, foi realizada a coleta de parte aérea e das raízes para determinação da massa seca de raízes e de parte aérea. O fomesafen apresentou potencial de uso para o algodoeiro, cultivar FM 993, todavia, os sintomas de fitointoxicação foram muito intensos nas plantas tratadas com as maiores doses no solo de textura franco arenosa. Desta forma, deve-se ajustar a dose de fomesafen de acordo com a classe textural e o teor de matéria orgânica do solo.

Palavras-chaves: classe textural, fitointoxicação, Gossypium hirsutum r. Latifolia, inibidor de Protox

\footnotetext{
Abstract - The selectivity of pre-emergence herbicides depend of the soil characteristics. In this context, the aim of this works was evaluated the fomesafen selectivity to cotton crop in soil with contrasting textural class. The experiment was performed under greenhouse conditions in completely randomized design, with five replications. The treatments were organized in factorial arrangement $5 \times 2$, with the first level representing five doses of fomesafen $(0,175,350,525$ e 700 $\left.\mathrm{g} \mathrm{ha}^{-1}\right)$ and the second factor two soils with contrasting texture: sandy loam texture $\left(200 \mathrm{~g} \mathrm{~kg}^{-1}\right.$ of

${ }^{1}$ Recebido para publicação em 21/09/2014 e aceito em 15/07/2015.

${ }^{2}$ Acadêmico do Programa de Pós-graduação em Agronomia da Universidade Estadual do Centro-Oeste (Unicentro), Campus Guarapuava - PR. E-mail: <ra-karpinski@hotmail.com>; <andrepazinato0@gmail.com>.

${ }^{3}$ Pós-doutorando pela Universidade Federal de Pelotas/Epagri Estação Experimental de Itajaí. Itajaí - SC. E-mail: <am.oliveiraneto@gmail.com>.

${ }^{4}$ Docente do curso de Agronomia da Universidade Federal de Santa Catarina (UFSC), Campus Curitibanos - SC. Email: <naiaraguerra.ng@gmail.com>.

${ }^{5}$ Docente do curso de Agronomia da Universidade Estadual de Maringá (UEM), Campus Maringá - PR, E-mail: <contantin@teracom.com.br>; <rsojunior@uem.br>.

${ }^{6}$ Docente do curso de Agronomia da Universidade Estadual do Centro-Oeste (Unicentro), Campus Guarapuava - PR. E-mail: <macielconsultoria@ hotmail.com>.
} 
clay, $40 \mathrm{~g} \mathrm{~kg}^{-1}$ of silt and $760 \mathrm{~g} \mathrm{~kg}^{-1}$ of sand, $\mathrm{pH}$ de 4,47 e 1,59\% de O.M.) and clayey (760 $\mathrm{g} \mathrm{kg}^{-1}$ of clay, $110 \mathrm{~g} \mathrm{~kg}^{-1}$ of silt and $130 \mathrm{~g} \mathrm{~kg}^{-1}$ of sand, $\mathrm{pH} \mathrm{5,7} \mathrm{e} \mathrm{2,30 \%} \mathrm{de} \mathrm{O.M.).} \mathrm{The} \mathrm{evaluations}$ performed were the number of emerged plants at 7 and 14 days after emergence (DAE), phytointoxication at 7, 14 and 21 DAE. At 35 DAE, it was collected the shoot and the roots of cotton plants to determined the shoot and roots dry mass. Fomesafen presented potential to be used for cotton, cultivar FM 993, however, the phytointoxication symptoms was very intense in plants treated with high doses in sandy loam soil. Thus, the fomesafen doses need to be adjusted according to the textural class, and the content of organic matter of the soil.

Keywords: textural class, phytointoxication, Gossypium hirsutum r. Latifolia, Protox inhibitor

\section{Introdução}

O algodoeiro é uma das primeiras plantas domesticadas pelo homem, tendo registro de seu cultivo a mais de 4.000 anos. No Brasil, não se tem muitas informações sobre o início do cultivo desta espécie, somente se sabe que os índios já a cultivavam para o uso em tecidos e fios (Carvalho, 2008).

No cerrado brasileiro, inicialmente, o algodão foi utilizado pelos agricultores como uma alternativa para a rotação com a cultura da soja. Todavia, hoje o algodão é visto como uma grande oportunidade de negócio. Isso levou o estado do Mato Grosso a ser o maior produtor brasileiro de algodão em pluma, seguido dos estados da Bahia e Goiás (Conab, 2014). As condições de clima, relevo e nível tecnológico dos agricultores nestes estados têm proporcionado ótimos rendimentos (Embrapa, 2003). Segundo os relatórios do Mapa (2013), as perspectivas apontam que haverá aumento considerável na produção e exportação do algodão nos próximos dez anos, com uma taxa de crescimento de $5,1 \%$ ao ano, passando a produzir na safra 22/23 2,53 milhões de toneladas de pluma.

Uma das formas de se alcançar estas previsões é evitando a interferência das plantas daninhas por meio do controle químico, com aplicação de herbicidas nas plantas (pósemergência) ou no solo (pré-emergência). Em relação à dinâmica de herbicidas no solo, esta pode ser influenciada por processos de retenção, transformação e transporte do produto. A mobilidade do herbicida no solo influencia diretamente o seu desempenho no controle de plantas daninhas, a seletividade sobre plantas cultivadas e a sua dissipação no ambiente (Firmino et al., 2008).

No Brasil, existe uma grande variabilidade em termos de solo, no que concerne às características químicas, físicas e biológicas. Em relação às particularidades em termos de solos e clima, pouco se sabe a respeito do comportamento de herbicidas em solos brasileiros. Em decorrência da grande variabilidade dos solos, espera-se que a atividade dos herbicidas no solo também seja diferente (Inoue et al., 2009), o que consequentemente influi diretamente sobre a seletividade de herbicidas aplicados em préemergência.

A classe textural juntamente com o teor de matéria orgânica é um dos principais fatores envolvidos na dinâmica dos herbicidas no solo (Silva et al., 2013), sendo utilizado como parâmetro para a escolha de herbicidas e suas doses. Normalmente, a capacidade sortiva dos solos tem relação direta com o teor de argila. Destaca-se que a sorção pode ser considerada como o desaparecimento da substância química da solução do solo, que é uma variável composta pela interação de diversos fatores. Estes compreendem desde a estrutura química do herbicida, sua natureza ácida ou básica e fatores do solo como teor de matéria orgânica, $\mathrm{pH}$, classe textural, entre outras (Silva et al., 2007; Oliveira Jr.; Regitano, 2009; Oliveira; Brighenti, 2011).

Deste modo, fica evidente que as características físicas, químicas e biológicas do solo podem influenciar diretamente na sorção 
do herbicida ao solo, afetando a quantidade do produto disponível em solução. Portanto, baseado no que foi exposto, o presente estudo foi realizado como o objetivo de avaliar a seletividade do herbicida fomesafen ao algodoeiro, em aplicações de pré-emergência, em solos de classe textural contrastantes.

\section{Material e Métodos}

O experimento foi realizado na Faculdade Integrado de Campo Mourão, nos meses de outubro e novembro de 2013, em casa de vegetação. As coordenadas são: latitude $23^{\circ} 59^{\prime} 27^{\prime \prime} \mathrm{S}$ e longitude $52^{\circ} 21^{\prime} 42^{\prime \prime} \mathrm{O}$ e altitude de $532 \mathrm{~m}$.

Os solos utilizados como substratos no experimento foram coletados em duas localidades. A primeira amostra foi proveniente de área experimental da Faculdade Integrado de Campo Mourão, por sabidamente apresentar solos de textura muito argilosa. A segunda amostra de solo foi retirada em uma propriedade rural localizada no distrito de São Lourenço, município de Cianorte, por estar sobre o Arenito Caiuá, onde há o predomínio de solos de textura arenosa e média. Portanto, foram selecionados solos com textura contrastante. A caracterização física e química dos solos encontra-se na Tabela 1.

Tabela 1. Caracterização química e física de uma amostra dos solos usados no experimento. Campo Mourão, PR, 2013.

\begin{tabular}{lcc}
\hline & $\begin{array}{c}\text { Muito } \\
\text { argilosa }\end{array}$ & $\begin{array}{c}\text { Franco } \\
\text { arenosa }\end{array}$ \\
\hline pH em água & 5,70 & 5,43 \\
M.O. $(\%)$ & 2,30 & 1,59 \\
$\mathrm{H}+\mathrm{Al}\left(\mathrm{cmol}_{\mathrm{c}} \mathrm{dm}^{-3}\right)$ & 5,00 & 4,47 \\
Cálcio $\left(\mathrm{cmol}_{\mathrm{c}} \mathrm{dm}^{-3}\right)$ & 2,47 & 1,17 \\
Fósforo $\left(\mathrm{mg} \mathrm{dm}^{-3}\right)$ & 1,34 & 5,02 \\
Magnésio $\left(\mathrm{cmol}_{\mathrm{c}} \mathrm{dm}^{-3}\right)$ & 1,44 & 0,49 \\
Potássio $\left(\mathrm{cmol}_{\mathrm{c}} \mathrm{dm}^{-3}\right)$ & 0,10 & 0,07 \\
\hline Areia $\left(\mathrm{g} \mathrm{kg}^{-1}\right)$ & 130 & 760 \\
Silte $\left(\mathrm{g} \mathrm{kg}^{-1}\right)$ & 110 & 200 \\
Argila $\left(\mathrm{g} \mathrm{kg}^{-1}\right)$ & 760 & 40 \\
\hline Análise realizada no Laboratório de Análises Físicas e Químicas \\
de Solo da Faculdade Integrado de Campo Mourão.
\end{tabular}

Cada solo foi peneirado, com a finalidade de retirada dos torrões e dos resíduos vegetais mais grosseiros. Posteriormente, o mesmo foi acondicionado em vasos de polietileno com capacidade de $5 \mathrm{dm}^{-3}$. A adubação de manutenção foi realizada com o formulado 15-20-20 na dosagem equivalente a $300 \mathrm{~kg} \mathrm{ha}^{-1}$. A semeadura foi realizada no dia 8 de outubro de 2013, sendo que cada unidade experimental recebeu oito sementes de algodão, da cultivar FM 993, a cerca de três centímetros de profundidade. Após a semeadura foi realizada a irrigação dos vasos. Decorridos 14 dias após a emergência do algodoeiro realizouse o desbaste, mantendo duas plantas por vaso.

$\mathrm{O}$ delineamento experimental adotado foi o inteiramente casualizado (DIC), com cinco repetições, organizados em esquema fatorial $5 \mathrm{x}$ 2. O primeiro fator consistiu de cinco doses de fomesafen $\left(0,175,350,525\right.$ e $700 \mathrm{~g}$ i.a. ha $\left.{ }^{-1}\right) . O$ segundo fator foi composto por dois solos de textura contrastante (textura franco arenosa e muito argilosa).

A aplicação dos tratamentos foi realizada no dia oito de outubro de 2013. As condições do tempo no momento da aplicação eram as seguintes: temperatura média do ar de $24,6{ }^{\circ} \mathrm{C}$, umidade relativa do ar de $69 \%$ e velocidade do vento de $1,8 \mathrm{~km} \mathrm{~h}^{-1}$, e o solo estava úmido em decorrência da irrigação. Para aplicação dos tratamentos utilizou-se um pulverizador costal pressurizado à $\mathrm{CO}_{2}$, equipado com 4 pontas de jato leque do tipo AVI ISO 110.02, a uma pressão de 30 psi o que proporcionou uma taxa de aplicação equivalente a $200 \mathrm{~L} \mathrm{ha}^{-1}$.

Durante a condução do experimento foi realizada a retirada manual das plantas daninhas diariamente. Realizou-se a aplicação do acaricida flufenoxurom (Cascade ${ }^{\circledR}$ 100) na dosagem de 150 g i.a. ha ${ }^{-1}$ para o controle do ácaro rajado (Tetranychus urticae). Além desta aplicação tornou-se necessária ainda uma aplicação do fungicida carbendazim (Carbendazim Nortox ${ }^{\circledR}$ ) na dose de 300 g i.a. ha ${ }^{-}$ ${ }^{1}$ e de piraclostrobina + epoxiconazol $\left(\right.$ Opera $\left.^{\circledR}\right)$ 
na dosagem de $183 \mathrm{~g}$ i.a ha ${ }^{-1}$. A irrigação foi realizada diariamente de modo a evitar o déficit hídrico.

As avaliações de fitointoxicação foram realizadas aos 7, 14 e 21 dias após a emergência das plântulas do algodoeiro (DAE), para isso utilizou-se a escala EWRC (1964) atribuindo notas de 1 a 9 para os sintomas visuais de fitoxicidade. Sendo que a nota 1 corresponde a nenhum dano visual às plantas e a nota 9 , significa a morte das mesmas.

Avaliações de contagem do número de plantas emergidas por unidade experimental foram realizadas aos 7 e 14 DAE.

Aos 35 dias após a emergência (DAE), foi avaliada a massa seca da parte aérea e a massa seca das raízes. Para isso, a parte aérea e as raízes foram acondicionadas em sacos de papel devidamente identificados, colocando-os posteriormente para secagem durante $72 \mathrm{~h}$ em estufa de ar de circulação forçada numa temperatura de aproximadamente $65^{\circ} \mathrm{C}$
(Sutclife, 1980). Em seguida, determinou-se a massa seca de parte aérea e das raízes através de pesagem em balança de precisão.

Os dados obtidos foram submetidos à análise de variância pelo teste $\mathrm{F}$ e as médias foram submetidas à análise de regressão, tanto o teste $\mathrm{F}$ quando os parâmetros da equação foram testados a uma probabilidade de 5\%. O modelo matemático ajustado foi o linear $(y=a \cdot x+b)$, em que y representa a variável resposta, o parâmetro a o coeficiente angular da reta, o $\mathbf{x}$ a dose do herbicida fomesafen e o $\mathbf{b}$ representa a interceptação da reta com o eixo vertical. As análises foram realizadas com o auxílio do programa estatístico Sisvar (Ferreira, 2011).

\section{Resultados e Discussão}

Aos 7 DAE foram observados sintomas visuais de fitointoxicação nas plantas de algodão, independentemente da classe textural do solo (Tabela 2).

Tabela 2. Fitointoxicação (escala EWRC ${ }^{1 /}$ ) observada na cultivar FM 993, decorridos 7 DAE, com aplicação de fomesafen em pré-emergência. Campo Mourão, PR, 2013.

\begin{tabular}{ccc}
\hline \multirow{2}{*}{ Fomesafen $\left(\mathrm{g} \mathrm{ha}^{-1}\right)$} & \multicolumn{2}{c}{ Textura do solo } \\
\cline { 2 - 3 } & Franco arenosa & Muito argilosa \\
\hline 0 & 1,0 & 1,0 \\
355 & 2,6 & 1,0 \\
525 & 3,0 & 1,8 \\
700 & 3,2 & 2,4 \\
\hline
\end{tabular}

1ㅌWRC: 1: ausência de sintomas e 9: morte da planta.

Os sintomas eram caracterizados por manchas necróticas distribuídas predominantemente na folha cotiledonar, encarquilhamento da borda da folha cotiledonar e em alguns casos, se observou o anelamento do caule próximo à região do colo. Os sintomas foram agravados no solo de textura franco arenosa, ocasionando a inibição da emergência de plântulas nas doses mais elevadas. Isto leva a inferir que neste tipo de solo houve maior concentração do herbicida na solução do solo. Este fato corrobora com o relato de Cobucci et al. (1997) ao sugerir que deve ser criterioso no momento da escolha e utilização do fomesafen em solos com baixos teores de argila e matéria orgânica para que não se tenha problemas de fitointoxicação e/ou carryover nas culturas sucedâneas como, por exemplo, o milho.

Main et al. (2012), estudando a tolerância do algodoeiro ao fomesafen, identificaram vários danos à cultura, como a redução na altura de plantas, redução no estande, necrose foliar e redução na 
produtividade de fibra, sendo a severidade dos danos variável com a dose de fomesafen.

A dosagem foi outro fator importante, já que no solo de textura muito argilosa, a menor dose aplicada não afetou a cultura (Tabela 2). Já no solo de textura franco arenosa, esta dose promoveu sintomas visuais de fitointoxicação ao algodoeiro. A diferença de intoxicação entre os dois tipos de solo foi significativa visto que as notas recebidas pelas plantas tratadas com a dose de $700 \mathrm{~g} \mathrm{ha}^{-1}$ no solo de textura franco arenosa foram superiores àquelas atribuídas para o solo de textura muito argilosa.

Sabe-se que o fomesafen é uma molécula que tem alta mobilidade no solo (Koc de 60), possui uma persistência mediana no ambiente, com uma meia vida de 100 dias, se enquadra como um herbicida lixiviável segundo os critérios de potencial de lixiviação do índice GUS (Gustafson, 1989; Oliveira Jr.; Regitano, 2009). É um herbicida que apresenta alta afinidade com a matéria orgânica, com Kow de 794 (Rodrigues; Almeida, 2011). Estas informações embasam o entendimento sobre a maior intensidade das injúrias no solo de textura franco arenosa, pois a combinação de irrigações diárias e menores teores de argila e matéria orgânica favorecem o carreamento e a maior concentração de fomesafen na região próxima a semente (Silva et al., 2013; Silva et al., 2014), portanto, durante a embebição das sementes, pode ter havido maior absorção do herbicida nesta classe textural.

Aos 14 dias após a emergência, houve leve diminuição dos sintomas de fitointoxicação causada pelo fomesafen, com destaque para as plantas cultivadas em solo de textura muito argilosa, que tiveram recuperação mais rápida quando comparadas ao outro solo (Tabela 3). As plantas tratadas com a maior dosagem de fomesafen tiveram menor recuperação. Decorridos 21 dias da emergência do algodoeiro, não foram observados quaisquer sintomas visuais de fitointoxicação. Contudo, era nítido o menor desenvolvimento das plantas no solo de textura franco arenosa.

Tabela 3. Fitointoxicação (escala $\mathrm{EWRC}^{1 /}$ ) observada na cultivar FM 993, decorridos 14 DAE, com aplicação de fomesafen em pré-emergência. Campo Mourão, PR, 2013.

\begin{tabular}{ccc}
\hline \multirow{2}{*}{ Fomesafen $\left(\mathrm{g} \mathrm{ha}^{-1}\right)$} & \multicolumn{2}{c}{ Textura do solo } \\
\cline { 2 - 3 } & Franco arenosa & Muito argilosa \\
\hline 0 & 1,0 & 1,0 \\
350 & 2,2 & 1,2 \\
525 & 2,6 & 1,4 \\
700 & 3,2 & 1,8 \\
\end{tabular}

1/EWRC: 1: ausência de sintomas e 9: morte da planta.

Houve redução linear no número plantas por vaso com o aumento na dose de fomesafen, para o solo de textura franco arenosa, enquanto que para o solo de textura muito argilosa, não houve influência da dose de fomesafen sobre o número de plantas emergidas (Figura 1A).

Sabe-se que o fomesafen é um herbicida lixiviável (Oliveira Jr.; Regitano, 2009) e que apresenta baixa sorção em solos com baixos teores de argila e matéria orgânica (Silva et al., 2013). Em sua pesquisa, Weissler e Poole
(1982) determinaram a quantidade de fomesafen na camada de $0-10 \mathrm{~cm}$ em solos com 6,0 e $2,1 \%$ de matéria orgânica; os mesmos pesquisadores observaram maior concentração de fomesafen $\left(185 \mathrm{mg} \mathrm{dm}^{-3}\right)$ no solo com maior teor de matéria orgânica, comprovando a matéria orgânica do solo contribui positivamente com a sorção do fomesafen. Neste sentido, os resultados obtidos podem estar associados às diferenças quanto a capacidade de sorção dos solos avaliados. 

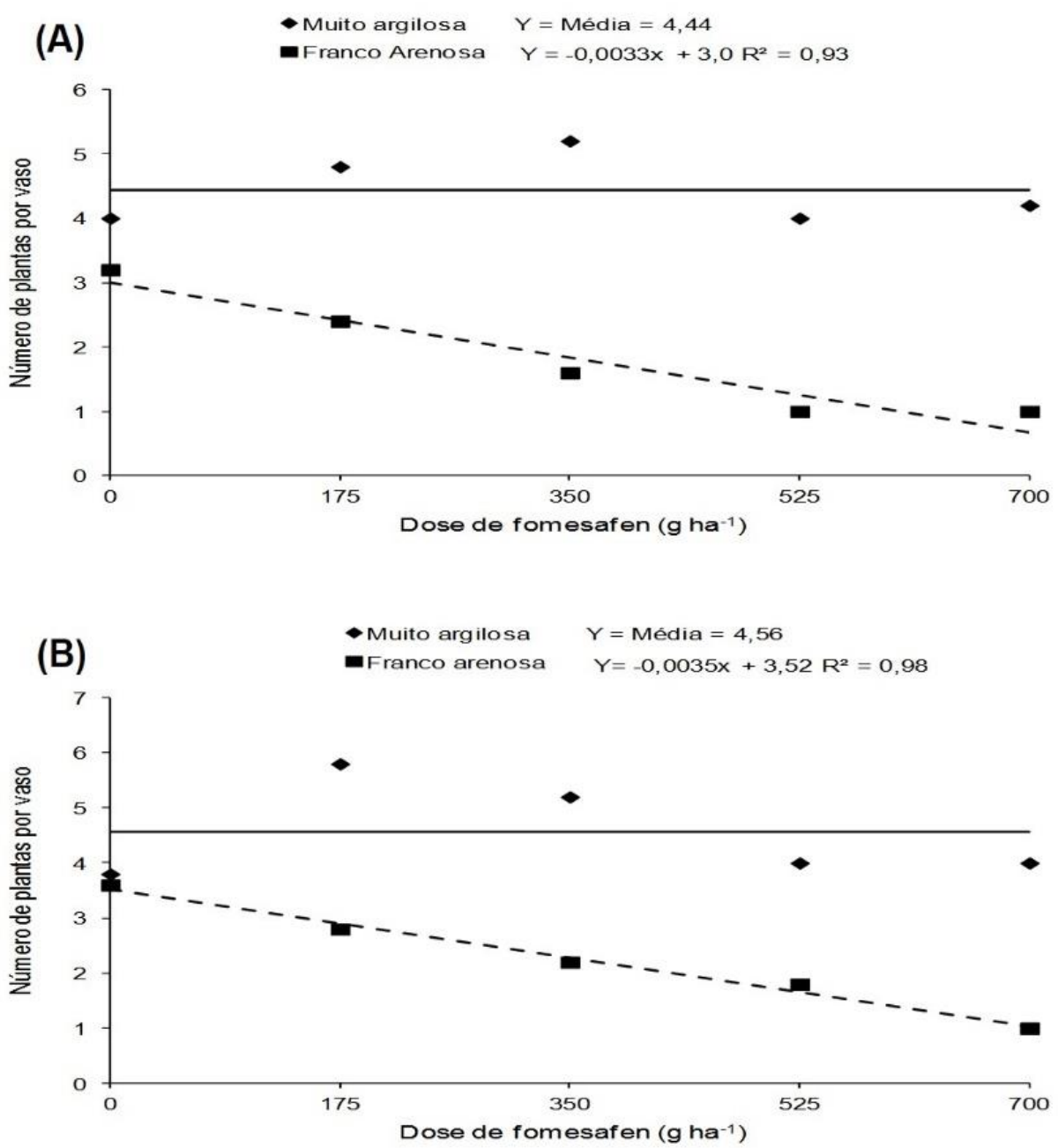

Figura 1. Número de plantas de algodoeiro emergidas por vaso aos 7 (A) e 14 (B) DAE, com aplicação de fomesafen em pré-emergência. Campo Mourão, PR, 2013.

Segundo Main et al. (2012), a precipitação pluvial pode influenciar a mobilidade dos herbicidas no solo, posicionando-os de maneira que a planta o absorva de forma mais eficiente, sendo que muitas vezes a profundidade de lixiviação dos herbicidas aplicados ao solo afeta a seletividade destes às culturas. Portanto, as irrigações diárias realizadas antes da emergência das plântulas de algodoeiro, possivelmente, contribuíram para carrear o fomesafen para mais próximo das sementes. Além disso, infere-se que a quantidade de fomesafen carreada foi maior no solo de textura franco arenosa, o que provocou a morte das plântulas antes que elas emergissem.
Main et al. (2012) relataram que solo com baixos teores de matéria orgânica $(<1 \%)$, aliado a ocorrência de precipitações, no período entre a semeadura e a emergência do algodoeiro favorecem o aumento nos níveis de fitointoxicação e redução no estande da cultura. Esta condição é muito semelhante à obtida no solo de classe textural franco arenosa.

Os resultados obtidos na avaliação de 14 DAE foram semelhantes aos descritos na avaliação anterior (Figura 1B). Este efeito pode restringir o uso de fomesafen em solos de textura arenosa e média e que apresentem baixos teores de matéria orgânica, principalmente de doses superiores a $175 \mathrm{~g} \mathrm{ha}^{-1}$, pois pode levar ao comprometimento irreversível do estande. 
Prata e Lavorenti (2000) citam que o teor de matéria orgânica tem correlação positiva com a sorção do herbicida no solo, sendo que quanto menor a quantidade de carbono aromático do composto húmico, maior a capacidade de sorção. Aliados a isto, sabe-se que os solos mais intemperizados e constituídos por minerais de argila de pouca atividade, como o solo de textura franco arenosa utilizado no experimento, têm a dinâmica de herbicida influenciada por outros fatores, como a capacidade de troca de cátions (Paulo et al., 1986). Ou seja, os efeitos mais intensos de fomesafen ao algodoeiro no solo de textura franco arenosa devem-se a fatores como menor teor de matéria orgânica e argila, baixa capacidade de troca de cátions e maior capacidade de drenagem de água (maior percolação do herbicida).

As doses de fomesafen não alteraram a massa seca da parte aérea e de raízes do algodão em solo de textura muito argilosa. No entanto, o aumento da dose do herbicida em solo de textura franco arenosa promoveu decréscimo linear na produção de massa seca de parte aérea e raízes da cultura (Figura 2A e B).
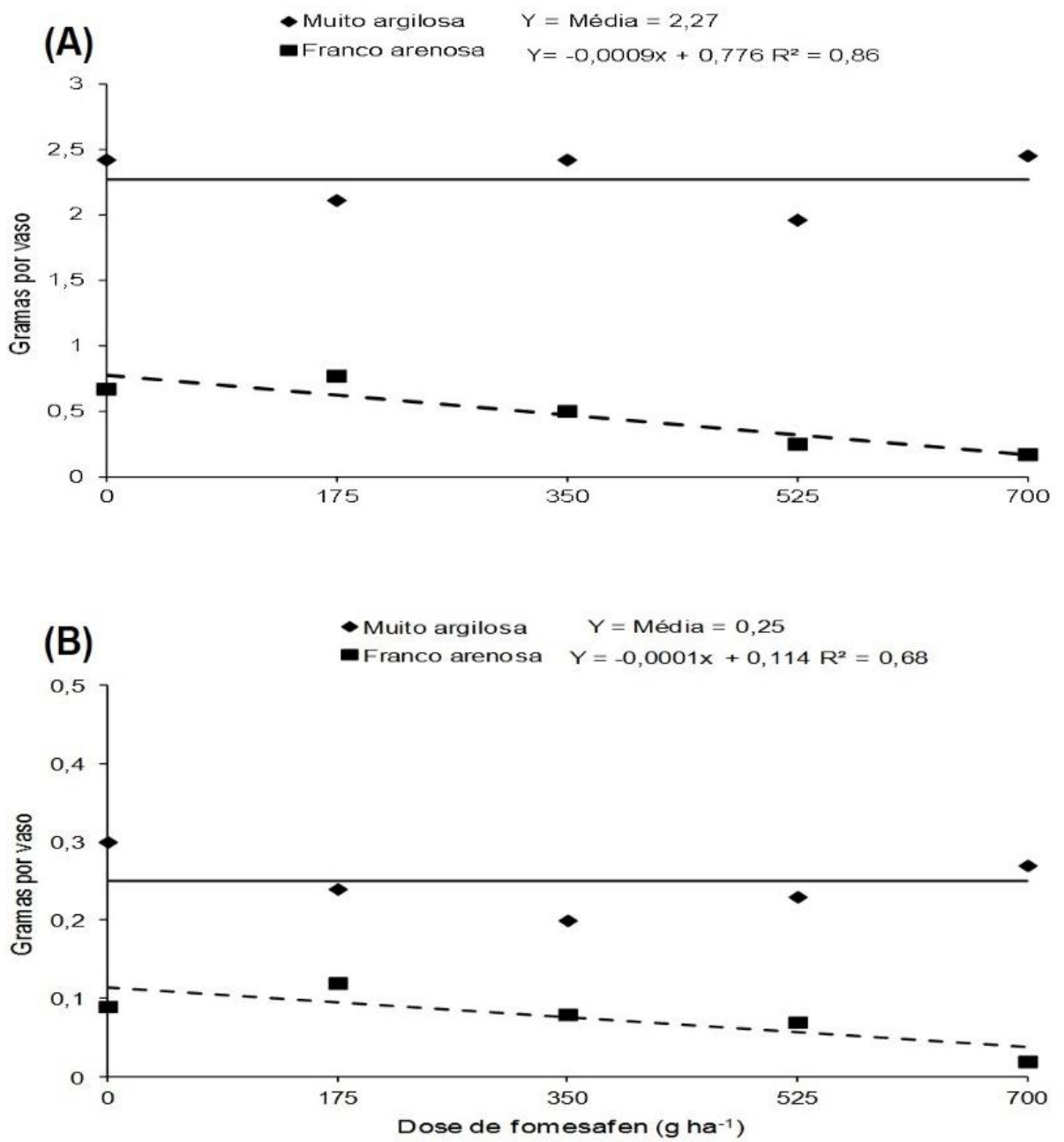

Figura 2. Massa seca da parte aérea (A) e das raízes (B) do algodoeiro aos 35 DAE, com aplicação de fomesafen em pré-emergência. Campo Mourão, PR, 2013.

Silva et al. (2013), estudando a sorção do Cambissolo e Organossolo), constataram que a fomesafen nos solos brasileiros (Argissolo, matéria orgânica e minerais de argila são os 
atributos de grande importância na sorção do fomesafen, sendo o coeficiente de sorção de fomesafen em Organossolo maior que em Argissolos e Cambissolos. Silva et al. (2014) avaliando o potencial de lixiviação do herbicida fomesafen em diferentes solos brasileiros, relataram que o principal fator que influenciou a lixiviação do fomesafen foi a matéria orgânica, seguido da textura do solo. Desta forma, fica evidente que as características do solo afetam significativamente a dinâmica do fomesafen no solo e, consequentemente, a sua seletividade ao algodoeiro. Além disso, o uso de doses inadequadas de fomesafen, principalmente em solos de textura arenosa e com baixos teores de matéria orgânica, pode comprometer irreversivelmente o estande do algodoeiro. Estudos complementares em condição de campo, e em diferentes condições de clima e solo, são decisivos para uma recomendação técnica adequada deste herbicida para o algodoeiro.

\section{Conclusões}

O fomesafen foi seletivo ao algodoeiro, cultivar FM 993, em solo de textura muito argilosa.

O uso de doses inadequadas do fomesafen em solo de classe textural franco arenosa pode comprometer o estabelecimento e o crescimento do algodeiro.

\section{Referências}

CARVALHO, L.P. O gênero Gossypium e suas espécies cultivadas e silvestres. In: BELTRÃO, N.E.M.; AZEVEDO, D.M.P. O agronegócio do algodão no Brasil. 2.ed., Brasília: Embrapa, 2008. p. 251-270.

COBUCCI, T.; SILVA, J.B.; PRATES, T.P. Carryover effect of fomesafen, applied on edible bean, on sucessional maize, Planta Daninha, v.15, n.2, p. 180-189, 1997.

CONAB - Compania Nacional de Abastecimento. Acompanhamento da Safra
Brasileira de grãos. v.1 Safra 2013/2014. n.5quinto levantamento, fev. 2014. Disponível em: <http://www.conab.gov.br>. Acesso em: $12 \mathrm{de}$ fevereiro 2014.

EMBRAPA - Empresa Brasileira de Pesquisa Agropecuária. Cultura do algodão no Cerrado. EMBRAPA. Brasília. 2003. Disponível em: <http://www.embrapa.br> Acesso em: 26 de outubro de 2013.

EWRC (European Weed Research Council). Report of 3rd and 4th meetings of EWRC Committee of Methods in Weed Research. Weed Research, v.4, p.88, 1964.

FERREIRA, D.F. Sisvar: a computer statistical analysis system. Ciência Agrotecnologia, v. 35, n.6, p. 1039-1042, 2011.

FIRMINO, L.E.; TUFFI SANTOS, L.D.; FERREIRA, L.R.; FERREIRA, F.A.; QUIRINO, A.L.S. Movimento do herbicida imazapyr no perfil de solos tropicais. Planta Daninha, v.26, n.1, p.223-230, 2008.

GUSTAFSON, D.I. Groudwater ubiquity score: A simple method for assessing pesticide leachibility. Environ. Toxicol. Chem., v.8, p.339-357, 1989.

INOUE, M.H.; OLIVEIRA JR.; R.S.; CONSTANTIN, J.; ALONSO, D.G.; TORMENA, C.A. Bioavability of diuron, imazapic and isoxaflutole in soils of constrasting textures. Journal of Environmental Science and Health - Part B, v.44, n.8, p.757-763, 2009.

MAIN, C.L.; FAIRCLOTH, J.C.; STECKEL, L.E.; CULPEPPER, S.; YORK, A.C. Cotton tolerance to fomesafen applied preemergence. Journal of Cotton Science, v.16, n. 1, p.80-87. 2012.

MAPA - Ministério da Agricultura, Pecuária e Abastecimento. Projeções do agronegócio: Brasil 2012/2013 a 2022/2023, Assessoria de Gestão Estratégica. Brasília, 2013, 96 p. 
OLIVEIRA JR, R.S.; REGITANO, J. B. WEISSLER, M.S.; POOLE, N.J. Mobility of Dinâmica de pesticidas no solo. In: MELO, fomesafen and degradation products in soil V.F.; ALLEONI, L.R.F. (Org.). Química e columns. London, ICI, 1982.3p.

Mineralogia do Solo: Parte II - Aplicações. Viçosa: Sociedade Brasileira de Ciência do Solo, 2009, v. 2, p. 187-248.

OLIVEIRA, M.F.; BRIGHENTI, A.M. Comportamento dos herbicidas no ambiente. In: OLIVEIRA JUNIOR, R. S.; CONSTANTIN, J.; INOUE, M.H. Biologia e manejo de plantas daninhas. Curitiba: Omnipax, 2011. p. 261304.

PAULO, E.M.; JORGE, J.A.; ARRUDA, F.B.; PATRÍCIO, F.R.A. Efeitos de algumas características do solo na resposta da planta a doses de herbicidas. Planta Daninha, v.9, p.7684, 1986.

PRATA, F.; LAVORENTI, A. Comportamento de herbicidas no solo: Influência da matéria orgânica. Biociência, v.26, n.2, p.17-22, 2000.

RODRIGUES, B.N.; ALMEIDA, F.S. Guia de herbicidas. 6. ed. Londrina: Edição dos autores, 2011. 697p.

SILVA, A.A.; VIVIAN, R.; OLIVEIRA JR., R.S. Herbicidas: Comportamento no solo. In: SILVA, A.A.; SILVA, J.F. Tópicos em manejo de plantas daninhas. Viçosa: UFV, 2007. p. 189-248.

SILVA, G.R.; D'ANTONINO, L.; FAUSTINO, L.A.; SILVA, A.A.; FERREIRA, F.A.; TEXEIRA, C.C. Sorption of fomesafen in brazilian soils. Planta Daninha, v. 31, n. 4, p. 971-977, 2013.

SILVA, G.R.; D'ANTONINO, L.; FAUSTINO, L.A.; SILVA, A.A.; FERREIRA, F.A.; TEIXERA, C.C.; COSTA, A.I.G. Mobilidade do fomesafen em solos brasileiros. Planta Daninha, v.32, n.3, p.639-645, 2014.

SUTCLIFE, J.F. As plantas e a água. São Paulo: EPU/Edusp, 1980. p. 23. 